\title{
Histological Maturation of Astroglial Cells in the Archicortex of Early Malnourished Rats
}

\author{
MARÍA ELENA CORDERO, ABRAHAM ZVAIGHAFT, SANTIAGO MUZZO AND OSCAR BRUNSER ${ }^{[: 34}$ \\ Department of Basic Sciences, Faculty of Medicine, University of Chile, Santiago, [M.E.CJ and Institute of Nutrition \\ and Food Technology, University of Chile, Santiago, Chile [A.Z., S.M., O.B.]
}

\begin{abstract}
Summary
The maturation of fibrous astrocytes was studied in the archicortex (hippocampus) of rats subjected to early postnatal malnutrition. $A$ decrease in the number of protoplasmic processes and end-feet in fibrous astrocytes from the cortical molecular layer was observed. In animals refed after weaning the number of protoplasmic processes returned to normal while that of end-feet remained unchanged. The diameter of the perikaryon was reduced. It is postulated that early malnutrition, induced immediately after birth, impairs differentiation of astroglia in the archicortex of the rat brain, probably as a response secondary to altered neuronal and capillary development.
\end{abstract}

\section{Speculation}

The effect of early postnatal malnutrition is most severe in structures of the central nervous system which have the highest rates of growth and differentiation. Important, and sometimes lifelong, changes in brain structure and composition including neuronal damage have been demonstrated.

This study indicates that astroglial cells are also adversely affected by prolonged nutrient deprivation. These cells participate in neuronal metabolism and damage to them may contribute to intensify the effects of malnutrition upon the neurons.

Pre and postnatal development of various brain structures occur at well defined stages during central nervous system growth. In all mammals that have been studied so far, ontogenesis of the archicortex occurs relatively late during gestation and continues postnatally (4). It consists of a first stage characterized by mitotic division of cells in the matrix surrounding the ventricular surface, followed by their migration to the cortical plate. Cytodifferentiation begins in the deeper parts of the cortical plate and takes place successively in the inside to outside sequence that affects all layers (18).

Results of studies on mammals have discerned the critical importance of nutrient supply and environmental stimulation upon the maturation of brain structures $(13,20,25,32,33)$.

Early postnatal marasmus causes alterations in the central nervous system (35). The severity of these changes depends on the stage and on the timing (and therefore on the stage of brain development), and on the intensity of the nutrient deficiency (15). Both morphologic and biochemical parameters are affected (1-3, $7,10-12,14,17,19,20,21,22,24,29,31$ ).

The studies reported here focus on the consequences of malnutrition upon the histologic maturation of astroglial cells from the molecular layer of the dorsal hippocampus in rats. Astroglial cells are a component of the neuropil to which important roles on the metabolic and energetic mechanisms of nerve transmission have been attributed (30).

\section{MATERIALS AND METHODS}

Diets. The following diets were used throughout the experiment: a basal diet composed of corn starch $80 \%$, corn oil $10 \%$, non- nutritive cellulose $5 \%$, mineral mixture (37) $4 \%$, and vitamin mixture (38) $1 \%$. This diet provided from $9.7-10.3 \%$ protein (9). This amount of vitamins and minerals are known to support the optimal growth of rats.

Control diet. The control diet was obtained from "Alimentos Balanceados Ltd." Santiago, Chile. It provided the following: $22,8 \%$ protein, $5.9 \%$ fat, $46,8 \%$ carbohydrate, $6,5 \%$ ash, $6,0 \%$ fibre and $12 \%$ of water. Diets and drinking water were offered ad libitum.

Animals. Rats were obtained from the colony at the Institute of Nutrition and Food Technology (INTA). They originated from animals purchased from the Charles River Breeding Laboratories.

All dams were fed the control diet (22.8\% protein) while nursing. The following experimental groups were then formed: Group $I$, malnourished rats. Malnutrition was induced in the pups by the following method: 15 newborn male and female pups, weighing an average of $5 \mathrm{~g}$, were given to each dam to nurse. This number of nurslings per rat implies a higher competition for maternal milk, resulting in an inadequate intake. The pups were weaned on day 21 st and fed ad libitum the low (10\%) protein diet for 14 days. Mean body weight of the litters at weaning was $18 \mathrm{~g}$; at the end of the low-protein period it was $33.8 \mathrm{~g}$. Group 11 , refed rats. Male and female pups, malnourished during the nursing period as previously described and belonging to the same enlarged litters, were fed the $22.8 \%$ protein diet ad libitum for 14 days after weaning. After 14 days on this $22.8 \%$ protein diet, mean body weight had increased from $18 \mathrm{~g}$ at weaning to $56.0 \mathrm{~g}$. Group $I 11$, control rats. Litters of 8 newborn male and female rats of the stock of INTA were given to nurse to each dam. The pups were weaned on day 21 and then fed the $22.8 \%$ protein diet ad libitum for 14 days. At the time of weaning mean body weight was $35 \mathrm{~g}$. After 14 days on the normal protein diet this was $77.5 \mathrm{~g}$. All animals were housed under controlled temperature, humidity and lighting conditions.

Procedures. The effect of each diet was studied in at least five different litters. One rat from each litter was selected at random among those animals whose weight was within 2 standard deviations of the mean, giving a total of five rats per experimental group. The animals were killed by ether inhalation. The brain was carefully removed, sectioned along the sagittal plane and fixed by immersion in formalin-bromide solution for five days (8).

The right hemisphere was then divided into three slices of equal thickness by means of two parasagittal cuts. The inner and outer slices were discarded. The central slice corresponded approximately to the de Groot coordinates medial-lateral $1.5-3.5 \mathrm{~mm}$. After freezing, this central slices was cut at $30 \mu \mathrm{m}$ of thickness with a sliding microteme (26).

The section were stained in Cajal's gold sublimate for astrocytes, reduced, mounted with synthetic resin and examined at $\times 400$ magnification. These were studied by two independent observers with foreknowledge of the group the specimen belonged to.

All astrocytes from a 250 by $\mu \mathrm{m}$ square area of the molecular layer of the dorsal hippocampus adjacent to the fissure, approximately 1.2-3.2 mm of the de Groot coordinates rostro-caudal were studied. The areas is demarcated in Figure 1.

Five drawings were examined from each group of animals, one from each of the cerebri. Each drawing included from 60-80 


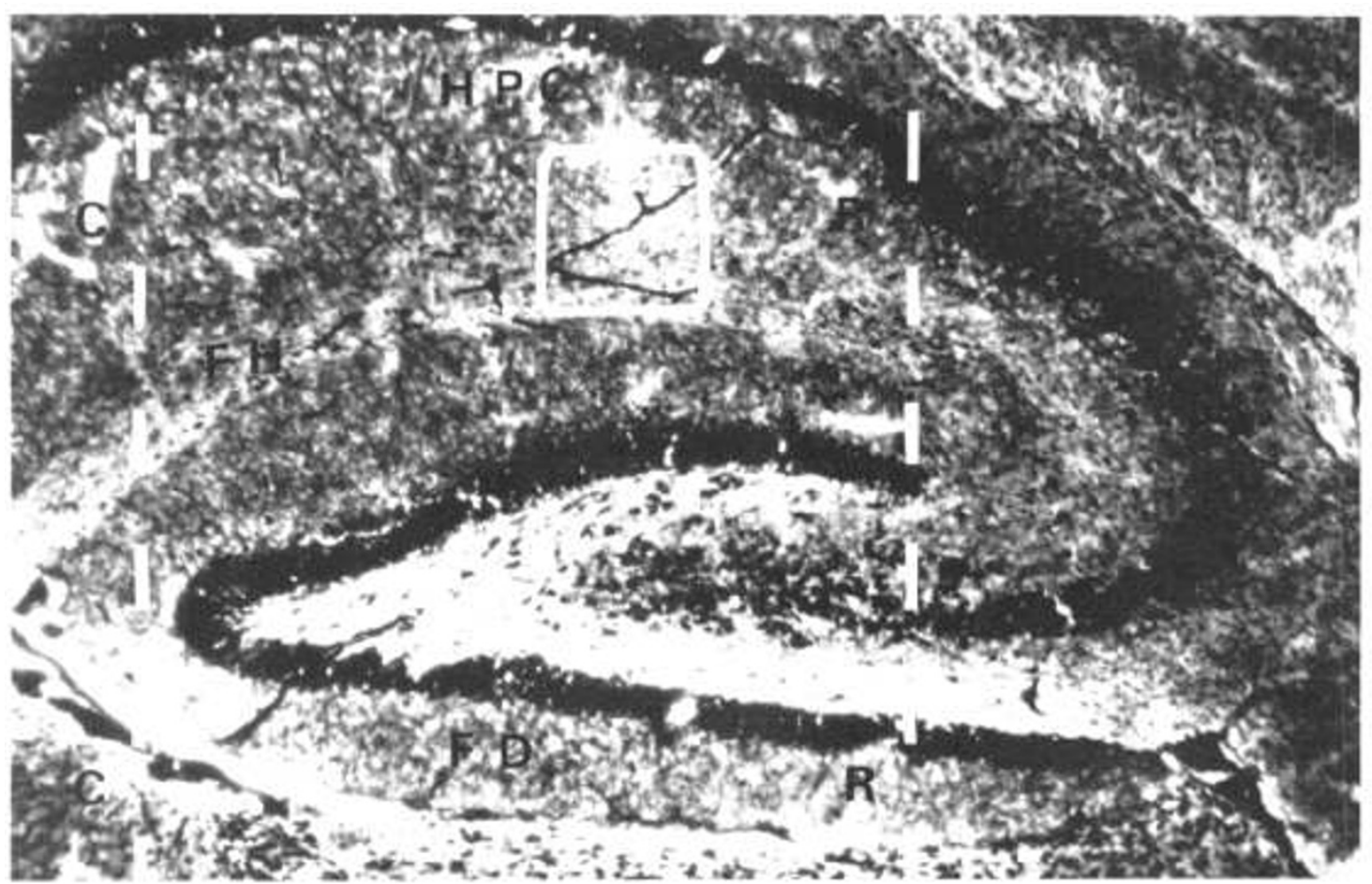

Fig. 1. Parasagittal section of archicortex in 35-day-old malnourished rat. The interrupted lines show the rostral (R) and caudal (C) limits of the archicortex. The fascia dentata (FD) is visible below the fissure hippocampi (FH). Astrocytes were examined in areas measuring 250 by 250 microns such as the one depicted in this picture. The small square in the molecular layer of the dorsal hippocampus, near the fissure (FH). Cajal gold sublimate, $\times 40$.

fibrous astrocytes (Fig. 2). Their perikaryon and prolongations (protoplasmic processes and end-feet) were drawn reproducing accurately each one of them over the full thickness of the section. The capillary network was also carefully drawn. The drawings were made on millimetric paper using an eye-piece with a reticulum of 100 squares and a Zeiss drawing attachment. At $\times 400$ magnification, each $2 \mathrm{~mm}$ on the paper was equivalent to $2.5 \mu$ on the histologic section. Measurement of the maximum diameter of the perikaryon and the length of the protoplasmic processes and end-feet were made by means of an eye-piece fitted with a scale at $\times 1000$ magnification. Fifty astrocytes in each group were chosen at random from the molecular layer of the dorsal hippocampus and measured.

\section{RESULTS}

Differences in the structural pattern of fibrous astrocytes from the archicortex of the cerebrum were found when normal and malnourished rats were compared.

Figure 3 depicts astrocytes from the molecular layer. Those of 21- and 35-day-old control rats are shown in Figure 3A and B. Astrocytes from malnourished animals of the same age groups are shown in Figures 3C and D. Astroglia from re-fed, 35-day-old rats are shown in Figure 3E.

Figure 4 illustrates some of the changes observed in astrocytes in malnourished and nutritionally rehabilitated rats. Cells from the controls appear in the upper part. On the left side, frame A illustrates astrocytes observed in 21-day-old control rats. Both the star-shaped perikaryon and the glial processes stain well. Several protoplasmic processes can be seen radiating from the cell body. On day 35 (frame B) astrocytes show well defined outlines, several protoplasmic processes radiating from the perikaryon and a number of end-feet. These usually terminate in more than one capillary (see also Fig. 3B). Astrocytes from malnourished animals are shown in the lower part of Fig. 4. The left side (frame C) illustrates the appearance most frequently found in rats malnourished for 21 days. These cells are more spindle-shaped and gold deposition is less dense and limited to the perikaryon and a few prolongations. Perivascular end-feet contact the wall of blood vessels by means of conical-shaped structures. Astrocytes of rats malnourished for 35 days (frame $D$ ) show gold deposition mainly in the perikaryon. Protoplasmic processes are usually thinner than in the controls. By contrast the end-feet are thicker. In rats malnourished until day 21 and subsequently re-fed until day 35 of life (frame E), astrocytes appear star-shaped, with more protoplasmic processes than in the two previous groups. However, irregularities in the thickness of the end-feet persists.

The number of prolongations, protoplasmic processes and endfeet of malnourished animals is compared with their age-matched controls in Table 1 . In 35-day-old malnourished rats (group D) a significant decrease in the number of prolongations, protoplasmic processes and end-feet per astrocyte is observed. Table 2 shows that at 35 days a significant decrease in the length of protoplasmic processes, end-feet and perikaryon diameter has taken place. There is no difference in the number of prolongations and of protoplasmic processes per astrocyte in malnourished animals refed from 21-35 days of age (E), compared to their age matched controls (Table 1). However the number of end-feet per cell is decreased (Table 1). While there is no difference in the length of end-feet and protoplasmic processes, a decrease in perikaryon diameter is observed in the re-fed rats (Table 2). Tables 1 and 2 also compare the results observed after 21 and 35 days of malnutrition (group C vs group D). In Table 2, significant reduction in perikaryon diameter and length of perivascular end-feet between $\mathrm{C}$ and $\mathrm{D}$ group is observed.

\section{DISCUSSION}

These observations indicate that severe malnutrition, occurring during the suckling period, impairs the histologic maturation of astrocytes in brain archicortex that normally occurs around day 15 of the postnatal life of rats (4). This damage could be explained by alterations in the sequence of the stages of the cerebral cortex morphogenesis. In the rat, early postnatal malnutrition induces a deficit in the number of brain cells (15-34), prolongs the time required for DNA synthesis (23), and retards the migration of glial cells into the cortical plate. Furthermore their alignment around nerve fibers is defective (6). The delay in astroglia matu- 


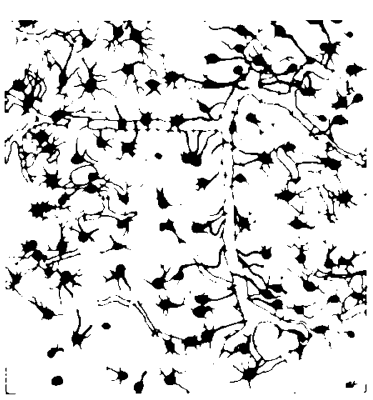

A

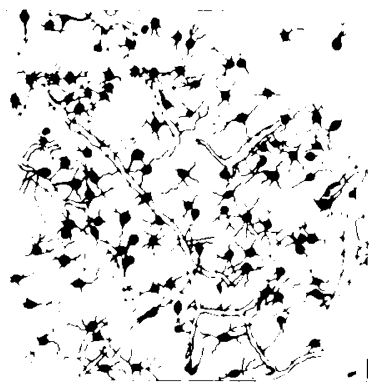

B

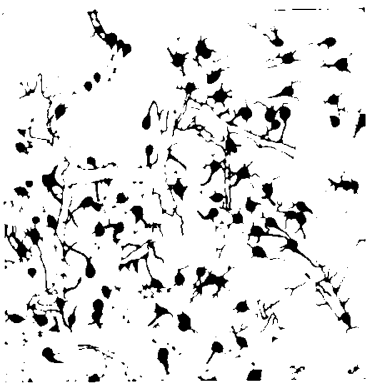

C

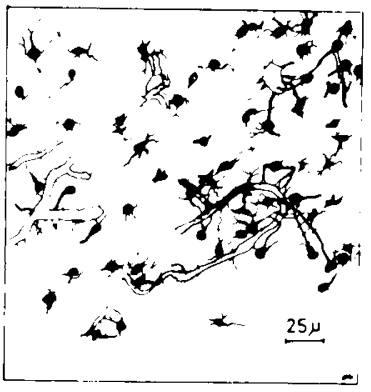

D

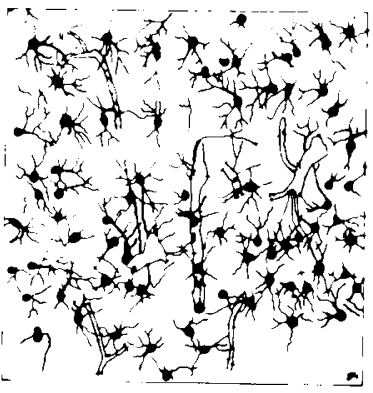

$\mathbf{E}$

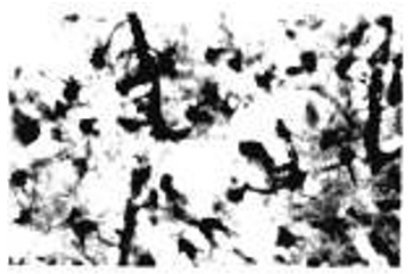

A

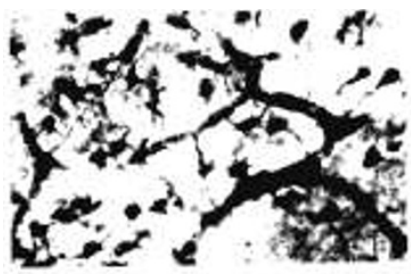

B
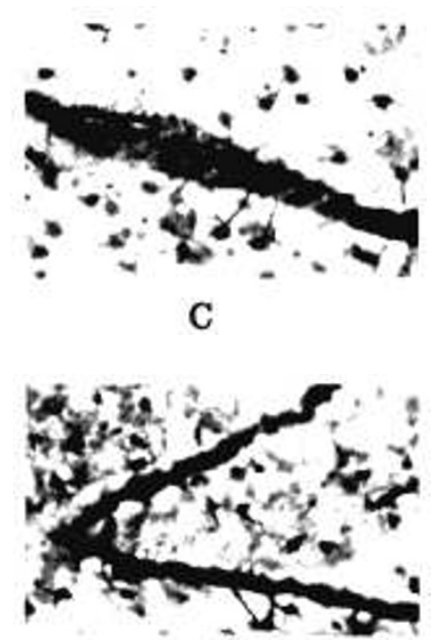

$\mathrm{D}$

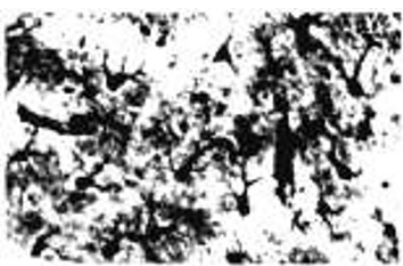

E

Fig. 3. Actual sections of rat archicortex, illustrating the same groups as in Figure 2. In 3B it is evident that astrocytes may have end-feet terminating in more than one capillary. Cajal gold sublimate, $\times 400$.

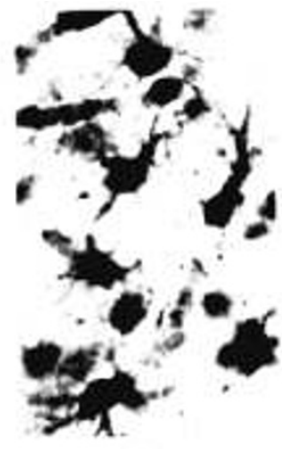

$\mathbf{A}$

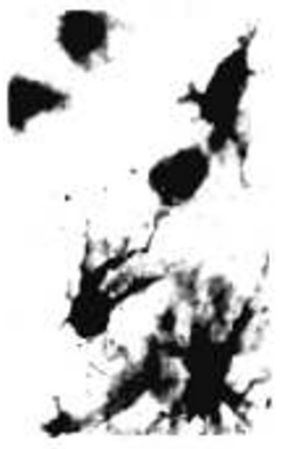

B

similar effects of nutrient restriction.

Spongioblast maturation is preceded in mammals by neuron differentiation in the cortical plate (5). Alterations of cellular differentation of the pyramidal cells of the layer $\mathrm{V}$ of the occipital cortex with decrease in the number and length of their basilar dendrites have been reported in malnourished rats (12). On the other hand, early postnatal malnutrition induces deficits in dendritic spine density in basilar dendrites of pyramidal cells of layer $\mathrm{V}$ of the occipital cortex (28). Rakić has observed a direct relationship between the development of dendritic spines and the growth of glial processes in Bergman astroglial cells in normal rhesus monkey cerebellum (27).

If it is postulated that glial differentiation depends on neuron differentiation (in parallel with what has been shown with oligodendroglial cells in relation to the axon), the deficit of astroglial maturation could be a consequence of previous damage to the neurons. The deficit of glial processes demonstrated by our research could be due to disturbances of the mechanism which induces differentiation of dendrites and dendritic spines. This in turn may contribute to alter the maturation of the protoplasmic processes of astrocytes.

Dyson and Jones (16) demonstrated persistence of inmature types of synapsis in late stages of synaptogenesis in cerebral cortex of malnourished rats. This is in agreement with our hypothesis

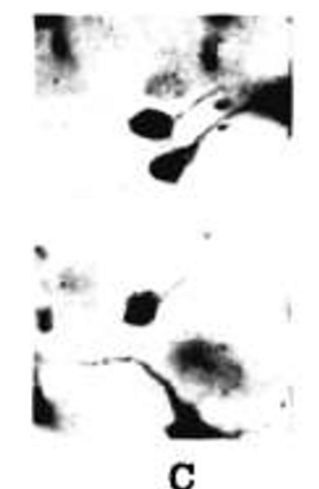

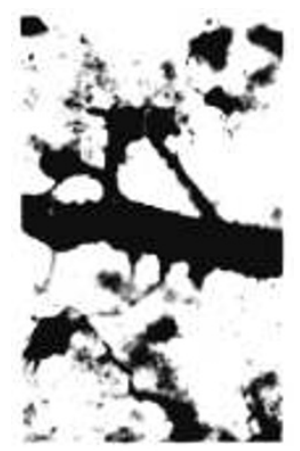

D

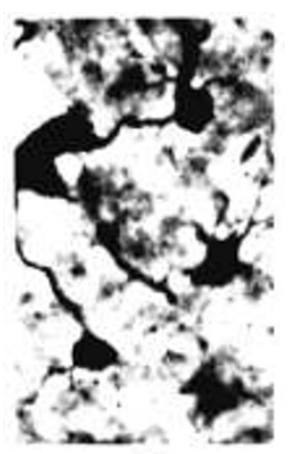

$\mathbf{E}$
Fig. 4. Archicortex of rats. Same nomenclature for the experimental groups as in Figures 2 and 3. Astrocytes in 21-day-old, malnourished rat (C) are spindle-shaped and with scant prolongations. End-feet of astrocytes in 35 day old malnourished rats (D) are thicker than normal controls of the same age. After nutritional rehabilitation (E) astrocytes recover their typical shape. Cajal gold sublimate, $\times 1000$. 
Table 1. Total number of prolongations, end-feet and protoplasmic processes per cell ${ }^{1}$

\begin{tabular}{|c|c|c|c|}
\hline & $\begin{array}{l}\text { Prolongations } \\
\text { per cell }\end{array}$ & $\begin{array}{c}\text { Protoplasmic } \\
\text { processes per } \\
\text { cell }\end{array}$ & $\begin{array}{l}\text { End-feet per } \\
\text { cell }\end{array}$ \\
\hline A & $\begin{array}{c}4.65 \pm 0.95^{2} \\
n=5\end{array}$ & $3.94 \pm 1.11$ & $0.72 \pm 0.25$ \\
\hline B & $\begin{array}{c}5.09 \pm 0.62 \\
n=5\end{array}$ & $4.34 \pm 0.59$ & $0.86 \pm 0.20$ \\
\hline $\mathrm{C}$ & $\begin{array}{c}3.59 \pm 0.88 \\
n=5\end{array}$ & $3.01 \pm 0.80$ & $0.57 \pm 0.18$ \\
\hline $\mathrm{C} v s \mathrm{~A}$ & N.S. & N.S. & N.S. \\
\hline D & $\begin{array}{c}3.21 \pm 0.47 \\
n=5\end{array}$ & $2.84 \pm 0.54$ & $0.36 \pm 0.11$ \\
\hline $\begin{array}{l}\mathrm{D} v s \mathrm{~B} \\
\mathrm{D} v s \mathrm{C}\end{array}$ & $\begin{array}{c}P<0.0005^{3} \\
\text { N.S. }\end{array}$ & $\begin{array}{c}P<0.0025 \\
\text { N.S. }\end{array}$ & $\begin{array}{c}P<0.0025 \\
\text { N.S. }\end{array}$ \\
\hline E & $\begin{array}{c}5.05 \pm 0.87 \\
n=5\end{array}$ & $4.53 \pm 1.0$ & $0.54 \pm 0.19$ \\
\hline $\mathrm{E} v s \mathrm{~B}$ & N.S. & N.S. & $P<0.025$ \\
\hline
\end{tabular}

' Average values of the number of prolongations, protoplasmic processes and end-feet.

${ }^{2}$ Standard deviation. Mean values were calculated from astrocytes present in each one of five drawings of each group in A: 21 day old control; B: 35 day old normal control; C: 21 day old malnourished; D: 35 day old malnourished and E: 35 day old nutritionally rehabilitated.

${ }^{3}$ Compared to age-matched control.

Table 2. Diameter of the perikaryon and length of protoplasmic processes and end-feet ${ }^{1}$

\begin{tabular}{cccc}
\hline & $\begin{array}{c}\text { Perikaryon } \\
\text { diameter }\end{array}$ & $\begin{array}{c}\text { Length of } \\
\text { protoplasmic } \\
\text { processes }\end{array}$ & $\begin{array}{c}\text { Length of } \\
\text { perivascular } \\
\text { end-feet }\end{array}$ \\
\hline A & $\begin{array}{c}9.06 \pm 0.30^{2} \\
n=5\end{array}$ & $9.42 \pm 0.59$ & $17.92 \pm 0.97$ \\
B & $\begin{array}{c}9.82 \pm 0.76 \\
n=5\end{array}$ & $11.4 \pm 1.61$ & $23.62 \pm 2.41$ \\
C & $\begin{array}{c}8.74 \pm 0.55 \\
n=5\end{array}$ & $8.1 \pm 1.32$ & $21.1 \pm 3.41$ \\
C vs A & N.S. & N.S. & N.S. \\
D & $\begin{array}{c}7.52 \pm 0.59 \\
n=5\end{array}$ & $8.88 \pm 2.05$ & $14.45 \pm 2.04$ \\
D vs B & $P<0.0005^{3}$ & $P<0.05$ & $P<0.0005$ \\
D vs C & $P<0.02$ & N.S. & $P<0.01$ \\
E & $8.86 \pm 0.44$ & $11.74 \pm 2.12$ & $23.98 \pm 3.98$ \\
E vs B & $P<0.05$ & N.S. & N.S. \\
\hline
\end{tabular}

'Average values of the perikaryon diameter and length of protoplasmic processes and end-feet per cell.

${ }^{2}$ Standard deviations. Values were calculated in 50 astrocytes (10 astrocytes for each cerebri) on 5 cerebrums of each group in A: 21 -day-old normal control; B: 35-day-old normal control; C: 21 -day-old malnourished; D: 35-day-old malnourished and E: 35-day-old nutritionally rehabilitated.

${ }^{3}$ Compared to age matched control.

that the disturbances of synaptic development could be associated to alterations in glial differentiation.

The deficit in maturation of astroglial cells observed at 35 days in malnourished rats was partially reversed after weaning by refeeding with an adequate diet for $2 \mathrm{wk}$. The number of prolon- gations per astrocyte became normal. This rehabilitation was apparently achieved by differentiation of new protoplasmic processes although a significant and persistent deficit of end-feet per astroglial cell persists. This indicates that during re-feeding recovery of some glial structures takes place and that, in rats malnourished up to 21 days of age, a certain potential for at least partial improvement exists. It is possible that the mechanisms which regulate astroglial differentiation are specific for each kind of prolongation. In addition some factors which induce end-feet differentiation may be related to the development of the vascular network. This contrasts with the irreversibility of the alteration induced by early malnutrition on the total cell number and on myelin synthesis (14-35).

When compared with 21-day-old malnourished animals (group C), rats fed the restricted diet until day 35 (group D), show, except for the length of the protoplasmic processes, a clear trend toward lower values for all the morphometric aspects studied. This trend is opposite to the changes due to age, since in group $B$ all values are higher than in group A. It may be postulated that these changes may be due to the more prolonged exposure to nutrient restriction. This is supported by observations carried out in our laboratory on the effects of early postnatal malnutrition on neuron maturation, in which reduced basilar dendritic arborization was found in the large pyramidal cells of the layer $V$ of the occipital cortex (12). In another study (36) on rats subjected to malnutrition from birth until day 60 of age, even lower values for dendritic arborization compared to rats malnourished until day 35 , has been observed. All these observations suggest that malnutrition may alter the ontogenetic stages of the brain cell population and that the duration of the nutrient deprivation contributes to make more apparent the disturbance. Some cell structures may be more vulnerable than others to the effects of nutrient deprivation. In adition, cells may adapt to malnutrition by protecting some of these components more efficiently. This could be the explanation why in our present observations, although the length of the protoplasmic processes of the astrocytes was slightly increased between days 21 and 35 of malnutrition, the other parameters suffered a reverse in the development steps.

This investigation suggests that early, severe and prolonged malnutrition interfers with the development of the astroglial cells. As astroglia has been shown to participate in the metabolic activities of neurons, this damage may contribute to further impair neuronal function in nutritional deprivation.

\section{REFERENCES AND NOTES}

1. Adlard, B. P. F., Dobbing, J. and Smart, J. L.: Undernutrition and the development of certain enzymes in rat brain. Biochem. J., 119:46 (1970).

2. Adlard, B. P. F. and Dobbing, J.: Vulnerability of developing brain. III. Development of four enzymes in the brains of normal and undernourished rats. Brain Res., 28: 97 (1971)

3. Adlard, B. P. F. and Dobbing, J.: Vulnerability of developing brain. Regional acetylcholinesterase activity in the brain of adult rats undernourished in early life. Brit. J. Nutr., 28: 139 (1972).

4. Altman, J. and Das, G. D.: Autoradiographic and histologic studies of postnatal neurogenesis. A. A longitudinal investigation of the kinetics. migration and transformation of cells incorporating triated thymidine in infants rats, with special reference to postnatal neurogenesis in some brain regions. J. Comp. Neurol., 126: 337 (1966).

5. Aström, K. E.: Cortical development in fetal sheeps. Progress in Brain Res., 26 . 1 (1967).

6. Bass N. H., Netsky, M. G. and Young. E.:Effect of neonatal malnutrition on developing cerebrum. II. Microchemical and histological study of myelin formation in the rat. Arch. Neurol., 23: 303 (1970).

7. Benton, J. W., Moser, H. W., Dodge, P. R. and Carr, S.: Modifications of the schedule of myelination in the rat by early nutritional deprivation. Pediatrics. 38: 801 (1966).

8. Cajal, S. R.: Ramon y Cajal's gold sublimate method for astrocytes. In: J. F. A Mc Manus, M.D. and Robert W. Mowry, M.D. Staining Methods. Histologic ald Histochemical p. 348 (A Hoeber International Reprint published by Hoeber Medical Division of Harper and Row 1964).

9. Chapman, D. G., Castillo, R.and Campbell, J. A.: Evaluation of protein in foods a. A method for the determination of protein efficiency ratios. Can. J. Biochem Physiol., 37: 679 (1959).

10. Chase. H. P., Dorsey, J. and Mackham. G. M.: The effect of malnutrition on the synthesis of a myelin lipid. Pediatrics, 40: 551 (1967).

11. Clark, C., Zamenhof, S., Van Marthens, E., Grabel, L. and Kruger. L.: The effect of malnutrition on dimensions of cerebral cortex. Brain Res. 54: 397 (1973). 
12. Cordero, M. E., Díaz, G. and Araya, J.: Neocortex development during severe malnutrition in the rat. Am. J. Clin. Nutr., 29: 358 (1976).

13. Cynader, M.. Berman, N. and Hein, A.: Recovery of function in cat visual cortex following prolonged deprivation. Exp. Brain Res., 25: 139 (1976).

14. Dobbing. J. and Widdowson. E. M.: The effect of undernutrition and subsequent rehabilitation on myelination of rat brain as measured by its composition. Brain, 88: 357 (1965).

15. Dobbing. J.: Human brain development and its vulnerability. In: Biologic and clinical aspects of brain development. p. 1. Mead Johnson Symposium on Perinatal and Development Medicine, No. 6, 1974.

16. Dyson, S. E. and Jones, D. G.: Some effects of undernutrition on synaptic development. A quantitative ultrastructural study. Brain Res., 114: 365 (1976).

17. Eckhert, C. R., Barnes, H. and Levitsky, D. A.: The effect of protein energy undernutrition induced during the period of suckling on cholinergic enzymes activity in the rat brain stem. Brain Res. 101: 372 (1976).

18. Fernández, V., Cordero, M. E. and Fuentes, I.: Autoradiographic study of the genesis of the cornu ammonis (archicortex) their relationship with the process of cellular differentiation. Informationnen Zur kernforschung und Kerntechnick. Nr. 3C 301042 (1973)

19. Frohman. M. A., Prensky, A. L. and Dodge, P. R.: Malnourished infants have small content of cerebral lipids. Nature, 22I: 552 (1969).

20. Grobstein, P. and Chow, K. L.: Receptive field organization in the mammalian visual cortex: the role of individual experience in development. In: G. Gottlieb: Neural and Behavioral specificity: studies on the development of behaviour and the Nervous System. Vol. 3, p. 155. Academic Press, New York, 1976.

21. Kerr, G. R. and Helmut, A. C.: Malnutrition studies in Macaca mulatta. 3. Effect on cerebral lipids. Am. J. Clin. Nutr., 26: 1053 (1973)

22. Krigman, M. R. and Hogan, E. L.: Undernutrition in the developing rat: effect upon myelination. Brain Res., 107: 239 (1976).

23. Lewis, P. D., Patel, A. J., Johnson, A. L. and Balazs, R.: Effect of thyroid deficiency on cell acquisition in the postnatal rat brain: A quantitative histological study. Brain Res., 104: 49 (1976).

24. Merat. A. and Dickerson. J. W.: The effect of the severity and timing of malnutrition brain gangliosides in the rat. Biol. Neonate, 25: 158 (1974).

25. Parnavelas, J., Globus, A. and Kanps, P.: Continuous illumination from birth affects spine density of neuron in the visual cortex of the rat. Exp. Neurol., 40: 742 (1973).

26. Pellegrino, J. L. and Cushman, J. A.: A sterotexic atlas of the rat brain Appleton-
Century-Crofts. New York (1967).

27. Rakić, P.: Neuronglia relationship during granule cell migration in developing cerebellar cortex. A Golgi and electromicroscopic study in macacus rhesus. J. Comp. Neurol.. 141: 283 (1971).

28. Salas, M., Diaz, S. and Nieto, A.: Effect of neonatal food deprivation on cortical spines and dendritic development of the rat. Brain Res., 73: 139 (1974).

29. Sereni, F., Principi, N., Perletty, L. and Sereni, P.: Undernutrition and the developing rat brain. I. Influence on acetylcholinesterasa and succinic acid dehydrogenase activities and on nor epinephrine and 5-OH triptamine tissue concentrations. Biol. Neonatorum, 10:254 (1966).

30. Sömen. G. G.: Electrophysiology of neuroglia. Ann. Rev. Physiol., 37: 163 (1975).

31. Stewart, R. J., Merat, A., Dickerson, J. W. C.: Effect of a low protein diet in mother rats on the structure of the brains of the offspring. Biol. Neonatorum. 25: 125 (1974).

32. Valverde, $F$.: Apical dendritic spines of the visual cortex and light deprivation in the mouse. Exp. Brain. Res., 3: 337 (1967).

33. Valverde, F.: Rate and extent of recovery from dark rearing in the visual cortex of the mouse. Exp. Brain. Res.. 33: 1 (1971).

34. Winick. M. and Noble, A.: Cellular response in rats during malnutrition at various age. J. Nutr., 89: 300 (1966).

35. Winick, M. and Rosso, P.: The effect of severe early malnutrition on cellular growth of human brain. Pediatr. Res., 3: 181 (1969).

36. To be published.

37. Mineral mixture (Hegsted): I g of mixture contains: $\mathrm{CaCO}_{3}, 300 \mathrm{mg} ; \mathrm{K}_{2} \mathrm{HPO}_{4}$, $323 \mathrm{mg}$ : $\mathrm{CaHPO} ; 4 \cdot 2 \mathrm{H}_{2} \mathrm{O}, 0.75 \mathrm{mg}$ : $\mathrm{MgSO}, \cdot 7 \mathrm{H}_{2} \mathrm{O}, 102 \mathrm{mg} . \mathrm{NaCl}, 168 \mathrm{mg}$ : $\mathrm{Fe}\left(\mathrm{C}_{6} \mathrm{H}_{5} \mathrm{O}_{7}\right)_{2} \cdot 6 \mathrm{H}_{2} \mathrm{O} ; \mathrm{KI}, 0.8 \mathrm{mg}: \mathrm{MnSO}_{4} \cdot 4 \mathrm{H}_{2} \mathrm{O}, 0.5 \mathrm{mg}: \mathrm{ZnCl}_{2}, 0.25 \mathrm{mg}$ and $\mathrm{CuSO}_{4} \cdot 5 \mathrm{H}_{2} \mathrm{O}, 0.3 \mathrm{mg}$.

38. Vitamin mixture: $1 \mathrm{~g}$ mixture contains: water soluble vitamins: choline hydrochloride, $200 \mathrm{mg}$ : $p$-aminobenzoic acid, $10 \mathrm{mg}$ : inositol, $25 \mathrm{mg}$ : niacin, $40 \mathrm{mg}$ : calcium panthothenate, $4.0 \mathrm{mg}$; riboflavin, $1.0 \mathrm{mg}$; thiamin hydrochloride, 0.5 $\mathrm{mg}$; pyridoxine hydrochloride, $0.4 \mathrm{mg}$; folic acid, $0.2 \mathrm{mg}$; biotin. $0.02 \mathrm{mg}$ : vitamin $B_{12}, 2 \mu \mathrm{g}$. Fat soluble vitamins: retinol, 200 IU; $\alpha$-tocopherol, 10 IU: cholecalciferol, $100 \mathrm{IU}$; menadione, $0.5 \mathrm{mg}$ and excipient, $1 \mathrm{~g}$.

39. Requests for reprints should be addressed to: Oscar Brunser, Institute of Nutrition and Food Technology. Casilla 15138, Santiago 11. Chile.

40. Received for publication November $5,1979$.

41. Accepted for publication April 21, 1981. 